

\section{"Isso é Pokémon, Mermão!": Sociabilidade e Apropriações de Pokémon Go na Cidade do Rio de Janeiro'}

"This is Pokémon, Bro!": Sociability
and Appropriations of Pokémon
Go in the City of Rio de Janeiro

Fátima Cristina Regis Martins de Oliveira ${ }^{2} \square$ Alessandra Cristina da Silva M. C. Monteiro ${ }^{3} \square$ Renata Cristina da Silva Monty Barretos ${ }^{4}[\pi$

\section{DOSSIÊ}

43 PORTO ALEGRE | v. 22 | n. 38 | 2017 | p. 43-52 DOI: http://dx.doi.org/10.15448/1980-3710.2017.2.29820 Sessões do Imaginário

\section{Resumo}

Este artigo visa investigar o fenômeno comunicacional desencadeado pela interação de jogadores com e pela cidade por meio da caça e treino de pokémons. A experiência preza pelo engajamento e exploração de diferentes áreas para subir de nível e coletar o máximo de honrarias virtuais. Essa interação social acontece tanto em sites de redes sociais quanto presencialmente. As diferentes fontes de observação reforçam a noção de uma cognição (Varela, 1994; Varela, Thompson, Rosch, 2000) na qual cérebro, corpo, objetos e ambiente são igualmente importantes para poder estudar um acontecimento em processo ou encerrado. Sendo assim, ela pode ser entendida como uma associação entre diferentes elementos que propiciam inúmeras maneiras de perceber a interação de jogadores-tecnologias-cidades.

\section{Palavras-chave}

Sociabilidade; apropriação; casual game; pokémon go; realidade aumentada.

\section{Abstract}

This article aims to investigate the communicational phenomenon triggered by the interaction of players with and by the city through the hunting and training of pokémons. The experience values the engagement and exploration of different areas to level up and collect the maximum of virtual honors. This social interaction happens on both social networking sites and in person. The different sources of observation reinforce the notion of a cognition (Varela, 1994; Varela, Thompson, Rosch, 2000) in which brain, body, objects and environment are equally important in order to study an in-process or closed event. Thus, it can be understood as an association between different elements that provide innumerable ways to perceive the interaction of players-technologies-cities.

\section{Keywords}

Sociability; appropriation; casual game; pokémon go; augmented reality. 


\section{Introdução}

Enquanto este artigo é redigido, o jogo Pokémon $G^{5}$ passa por inúmeras modificações e diferentes apropriações. Por essa razão é importante salientar que, como pesquisadoras da área de Comunicação Social, nos importam mais "os fenômenos comunicacionais mediados pelas mídias digitais, nos quais elas mesmas são também actantes" (Primo, 2013, p. 8) do que o software propriamente. Ou seja, importam os aspectos culturais relacionados à interação com o jogo e as redes sociais digitais e presenciais - aspectos que, por isso, são também cognitivos.

Não é de hoje que se discute a respeito do quanto a tecnologia tem tornado o ser humano mais solitário e recluso, em especial os jogos eletrônicos. Luís Mauro Sá Martino traz uma das críticas mais comuns: "O jogo é individual; fim das sociabilidades presenciais", e uma das possibilidades, "jogos permitem formas de sociabilidade digitais online" (Martino, 2014, p. 155). Isso, contudo, parece menos coerente quando se observa o sucesso de um jogo como o Pokémon Go que em julho de 2017 comemorou um ano de existência e reúne miIhões de pessoas pelo globo terrestre.

Os sites de redes sociais ainda são espaços muito utilizados, mas nota-se pela mecânica e regra básicas do jogo que é essencial explorar e desbravar a cidade, a fim de caçar e treinar Pokémons - assim, os jogadores exercem a dupla função de caçadores-treinadores. Isto é, para encontrá-los é necessário sair de casa, transitar por espaços públicos com seus smartphones em punho. No entanto, existem usuários que burlam a mecânica do jogo e usam aplicativos simuladores de posição, que possibilitam jogar sem sair da segurança de casa. Mas isso não é uma prática permitida - por esse motivo a Niantic tem a política de banir as contas que fazem uso de fakeGPS ${ }^{6}$, por exemplo, entre outros aplicativos e sistemas. Afinal, para jogar qualquer jogo é preciso seguir suas regras (Huizinga, 2007; Schell, 2008; Juul, 2005, 2014; Schuytema, 2016; Chandler, 2012; Rogers, 2012; Salen, Zimmerman, 2012; Martino, 2014).

Hábitos de consumo e de interação mediada são torcidos por uma mecânica que privilegia a relação do jogador com a cidade e seus diversos espaços. O engajamento é mensurado pela coleção de pokémons na pokédex (uma espécie de biblioteca) e pelas medalhas conquistadas. A experiência na cidade é ressignificada e transformada num misto de emoção e curiosidade, principalmente por causa da falta de segurança pública para transitar sem medo de ter o aparelho roubado, por exemplo. No caso do Rio de Janeiro, são recorrentes na internet algumas sátiras relacionadas à violência, com pokémons evoluindo com armas pesadas ou até mesmo praticando assaltos ${ }^{7}$. No site Nerdbloid ${ }^{8}$, um monstrinho está armado e a legenda é: "Esse daí foi capturado na Baía de Guanabara. Vai ajudar a enfrentar a criminalidade das Olimpíadas". No YouTube há ví$\operatorname{deos}^{9}$ com músicas sobre o jogo mescladas a registros de assaltantes no Centro do Rio, com o título Pokémon "versão Rio de Janeiro".

Ser um caçador e treinador de pokémons não é tão diferente de assumir um papel num jogo de representação de personagem (RPG), sendo considerada, segundo Janet Murray (2003), a forma mais antiga de engajamento do público, eles são teatrais de um modo não convencional, mas emocionante. Os jogadores são, ao mesmo tempo, atores e espectadores uns para os outros, e os eventos que encenam têm o imediatismo das experiências pessoais. Das quais os Alternate Reality $\mathrm{Ga}$ - mes (ARG, ou em português: jogos de realidade alternativa) fazem parte, eles são jogos cujo gameplay busca transitar entre a realidade concreta e a realidade virtual (Oliveira; Andrade, 2014) com o uso de múltiplas plataformas de comunicação. Ainda que para jogar Pokémon Go não seja imprescindível participar de inúmeros desafios espalhados por ambientes virtuais ou desvendar enigmas pela cidade para alcançar o objetivo.

Ressalta-se ainda que não consideramos que a interação do jogador entre a realidade virtual e física ocorra apenas num jogo de RPG ou de "realidade aumentada" (RA), pois jogos eletrônicos e analógicos de diferentes gêneros permitem que o gamer "entre" no personagem e tome as decisões necessárias para solucionar os desafios das fases. Entretanto, não há como negar que os comportamentos são modificados com a "mobilidade do jogo". Se numa partida de cartas, por exemplo, o jogador necessariamente utilizava um ponto fixo, em Pokémon Go uma característica essencial é movimentar-se por áreas distintas para ampliar as possibilidades de êxito. Há inúmeros relatos de jogadores em lugares inusitados, como no banheiro de casa, dentro do carro, na sala de aula, em museus e até cemitérios. Em lista divulgada pela Revista Galileu, jogadores mostravam-se em situações inesperadas, como o parto de um bebê, a reunião de uma gangue na Nova Zelândia e até pedindo permissão para entrar na Casa Branca, nos EUA (Vaiano, 2016).

Dada a importância social e cultural de um fenômeno que era considerado modismo passageiro, como o seu antecessor, o Ingress, que foi lançado em 2012, considera-se relevante as possibilidades de interação dentro e fora do jogo, digital e presencialmente. Sendo assim, na primeira seção faremos breve explanação 
sobre a ideia de uma cognição (Varela, 1994; Varela, Thompson, Rosch, 2000) que não se restringe às habilidades superiores da mente e pode ser compreendida como uma associação entre diferentes elementos que propiciam inúmeras maneiras de compreender a interação de jogadores-tecnologias-cidade. Para em seguida trazer esses elementos como integrantes do processo que enreda e dá vida a uma experiência de estar na cidade mediada pelo jogo, como é ser um aspirante a mestre pokémon numa cidade do Rio de Janeiro?

O trajeto desta pesquisa começou como uma espécie de observação do jogo e suas possibilidades de apropriação. Mas durante a redação do alicerce teórico, notou-se a importância de delimitar a pesquisa e tratar mais especificamente do espaço de interação numa cidade. A escolha do Rio se deu por ser a cidade na qual as quatro pesquisadoras residem e poderiam, além de analisar as postagens em grupos de Facebook ou fóruns específicos sobre o jogo, valer-se do método de observação participante com o intuito de registrar a experiência de caçar pokémons, duelar em ginásios adversários, defender e aumentar a confiança de seu time durante as batalhas, e encarar o Boss enquanto discretamente observavam a dinâmica de outros aspirantes a mestre pokémon, como realmente aconteceu.

\section{Cognição como associação}

Jogos são artefatos de interação, bem como a própria cidade. Essa sentença ajuda a compreender a ideia proposta pelos pesquisadores Francisco Varela, Evan Thompson e Eleanor Rosch (2000) sobre a cognição ser "antesa atuação deum mundoe de umamentecombase numa história da variedade das ações que um ser executa no mundo" (Varela, Thompson, Rosch, 2000, p. 32).
A perspectiva das ciências cognitivas adotada neste artigo tem o corpo, o ambiente, os objetos e as relações sociais como essenciais para compreender e agir no mundo. Em outras palavras, o ato de pensar está na associação da mente ao corpo e nas relações que este origina com aquilo que pode afetá-lo. Dessa forma, antes de realizar pesquisas de qualquer natureza, busca-se considerar o contexto no qual os produtos são desenvolvidos e/ou consumidos, porque isso ajuda a inferir algumas formas de agir e de se relacionar "com" e "a partir" deles. Por isso mesmo que "o contexto e o senso comum não são artefatos residuais que possam ser progressivamente eliminados graças a regras mais sofisticadas. São, na verdade, a própria essência da cognição criadora" (Varela, 1994, p. 78, grifo do autor).

Essa atuação é mútua e recíproca, não tem um elemento a priori mais importante, discussão que remete ao dito por Eduardo Galeano em entrevista (2011):

[...] Quando me chamam de distinto intelectual eu digo: não! Eu não sou um intelectual! Os intelectuais são os que divorciam a cabeça do corpo. Eu não quero ser uma cabeça que rola por aí! Eu sou uma pessoa! Sou cabeça, corpo, sexo, barriga, tudo! Mas não um intelectual, esse personagem abominável! Como dizia Goya: "A razão cria monstros".

Os pesquisadores enfatizam que toda forma de interação gera marcas que serão inscritas no espaço e no tempo, "o conhecimento depende de nos encontrarmos num mundo que é inseparável dos nossos corpos, da nossa linguagem e da nossa história social - em resumo, da nossa corporalidade" (Varela,Thompson, Rosch, 2000, p. 198, grifo nosso). Assim como destaca Frans Mäyrä,
[...] na maioria dos casos, não é razoável falar sobre o significado de um elemento de jogo desconectado, e até mesmo um jogo inteiro somente ganha importância quando experimentado por um jogador em um contexto cultural (Mäyrä, 2008, p. 19).

Para fins de categorização do jogo, além de fazer parte dos gêneros de RA e "baseado em geolocalização", consideramos que ele seja um casual game, porque o jogador não precisa explorar e/ou desenvolver habilidades muito específicas para conseguir jogá-lo, o que também permite observar o que acontece ao seu redor. Esta definição parte do entendimento de Laura Ermi e Frans Mäyrä (2011) quando discutem sobre a escolha de um jogo menos imersivo para que a atenção possa ser dividida entre ele e outras pessoas.

Na próxima seção, o estar com um olho no celular e o outro no espaço à sua volta será tratado, mas a ênfase recai sobre a questão do jogo como ambiente que pode fomentar interações virtuais e locais na busca de companhia para duelar contra um boss (chefão), ainda mais se for um pokémon raro.

\section{Pokémon Go: interações sociais digitais e presenciais}

Desde o seu lançamento, em julho de 2016, Pokémon Go é considerado um fenômeno de público. Ao conquistar 50 milhões de downloads em poucas horas, o aplicativo desenvolvido pela Niantic quebrou recordes e se tornou o "jogo mobile mais baixado em seu primeiro mês", segundo o Guinness World Record ${ }^{10}$, sem nem mesmo estar disponível para todos os continentes. Apesar da quebra de recordes, pouco mais de um 
mês após seu lançamento, houve um declínio no número de jogadores no mundo inteiro. De acordo com o gráfico da Bloomberg ${ }^{11}$, o jogo perdeu cerca de 15 miIhões de jogadores assim como o engajamento; e o número de downloads também diminuiu. Contudo, isso não significou a sua "morte". Mesmo com essas baixas, de acordo com os dados coletados pela empresa New$z^{200^{12}}$, o lucro continuou na casa de milhões/dia. A Niantic fatura cerca de U\$2 milhões/dia, em suas primeiras semanas chegou a alcançar a cifra de U\$16 milhões.

Cabe considerar que a popularização dos smartphones tornou viável a inserção de tecnologias como a realidade aumentada no cotidiano. Só no Brasil, são 198 milhões de aparelhos registrados até abril de 2017 e a estimativa é alcançar 236 milhões em até dois anos, segundo pesquisa da Fundação Getúlio Vargas de São Paulo $^{13}$ (FGV-SP). Se, por um lado, o acesso a celulares inteligentes viabilizou o uso da tecnologia de RA em larga escala e, consequentemente, a viralização de Pokémon Go, por outro, jogadores ainda relatam dificuldades para utilizá-la. Em geral, problemas de conexão e no sensor giroscópico travam o aplicativo. $\mathrm{O}$ consumo excessivo de bateria também é apontado como uma barreira operacional. A solução encontrada é desligar o modo RA, o que significa que a transmissão não terá a rua como pano de fundo, mas os cenários desenhados pela equipe de desenvolvedores. Como o interesse do público é grande pela nova tecnologia, há fóruns de discussão na web voltados para o uso de realidade aumentada em Pokémon Go e, ainda, listas com os celulares compatíveis.

É importante observar que, até o lançamento de Pokémon Go, os jogos de RA não atingiam o público em larga escala em todo o mundo. A principal carac- terística desses games é mesclar ambientes, públicos e privados, como residências, condomínios, praças e ruas, com interfaces virtuais, para atingir determinado objetivo. Em geral, são usados dispositivos móveis com câmeras equipadas com softwares programados para interpretar determinada informação do mundo físico e interagir com ele. No caso de Pokémon Go, o aplicativo usa o GPS do telefone para alertá-lo quando estiver próximo de uma personagem. Azevedo (2014, p. 175) faz uma definição desta tecnologia, ressaltando que a mistura de informações entre o mundo concreto e as virtualidades geram um híbrido de realidade. Nesse aspecto, no jogo Pokémon Go tem-se a sensação de que os inúmeros monstrinhos fazem parte do cotidiano, transformando espaços privados e urbanos.

Realidade aumentada, simplificadamente, é a inserção de elementos virtuais desenvolvidos por computação gráfica (bidimensionais e tridimensionais; estáticos e animados) sobre a realidade física capturada por dispositivos (fixos e móveis) dotados de câmeras audiovisuais, através de aplicativos específicos. De fato, o efeito que se obtém é a ampliação da cena capturada e o resultado da mistura de representações e simulações é uma imagem híbrida (Azevedo, 2014, p. 175).

Capture e duele com os seus Pokémons (contração das palavras Pocket Monsters, em inglês) para se tornar um mestre Pokémon. Essa é a premissa da experiência proposta pelo jogo, ela é simples e perpassa todos os produtos da franquia Pokémon, desde 1996'14. Assim, utilizando as tecnologias de RA e de "geolocalização", o objetivo do jogador é caçar e capturar pokémons ${ }^{15}$.
Para ter acesso a esse universo virtual e avançar no jogo para alcançar níveis mais altos o jogador precisa conquistar pontos de experiência (PE), é essencial se movimentar: ir até a pokéstop mais próxima, elas são estações nas quais é possível conseguir, além de $P E$, itens como pokébolas para capturar, "balas" para auxiliar a caçada e incentivar os seus e os pokémons de sua equipe quando estão defendendo um ginásio, "porções" e "revive" para recuperar as energias dos pokémons depois de um duelo, ovos de pokémon que poderão ser chocados enquanto se caminha com o aplicativo ativo e, em certas condições, item especial para evoluir alguns pokémons; e caçar os monstrinhos que surgem, a cada novo ser acrescentado à pokedex o jogador recebe $500 \mathrm{PE}$ e os repetidos rendem $100 \mathrm{PE}$, ao evoluir um pokémon o jogador também ganha pontos de experiência, mas para isso é preciso o doce do pokémon em questão; a conquista de medalhas no jogo permite angariar mais PE; entre outras ações.

Quando o jogador alcança o nível 5 e interage com um ginásio deve escolher um time que irá acompanhá-lo durante a sua jornada para se tornar um mestre pokémon. Esses times são Team Instinct (Time Instinto) - Cor Amarela, Team Mystic (Time Místico) - Cor Azul, e Team Valor (Time Valentia) - Cor Vermelha. No seu lançamento, os ginásios funcionavam como uma conquista de território e quanto mais prestígio tinham mais pokémons poderiam entrar, até 10 quando alcança esse nível. Para isso era preciso escolher os pokémons de acordo com as habilidades que seriam melhores para vencer cada tipo de defensor do ginásio, além de considerar os CP (Combat Power) e HP (Hit Points). Toda essa competitividade se dá não só pela conquista de território, mas também pelos benefícios que o jogador obteria 
após o feito, como pontos de prestígio e moedas para compra de itens na loja do jogo. Assim, quanto mais vitórias o time tivesse em um ginásio, mais prestígio teria, significando maior dificuldade para conquistá-lo.

Os ginásios eram definidos como inimigo e amigo, no primeiro era preciso atacar para reduzir o prestígio, mas só se ganhava os PE se vencesse todos os pokémons que o defendia; enquanto para subir o nível era necessário treinar os seus pokémons nos ginásios de sua equipe, ao conseguir entrar ganhava-se pokécoins (10 a cada 20 horas) para comprar itens na loja e Stardust (item também pode ser conquistado em outras ações do jogo) que junto ao doce ajuda a aumentar o CP e HP dos pokémons. Essa mecânica não exigia a interação local entre os jogadores, porque poderia ser demorado, mas com a redução do prestígio o nível baixava e o pokémon com o CP mais baixo saía do ginásio.

Após quase um ano de seu lançamento oficial, em 20 junho de 2017, a Niantic anunciou uma das atualizações ${ }^{16}$ mais esperadas do jogo que mudou completamente os ginásios. As batalhas agora podem ser colaborativas, permitem que se formem grupos privados de jogadores para derrotar um determinado "chefão", nas batalhas Raid"17. As mudanças significativas na mecânica de interação com os ginásios também contribuíram para transformar as relações sociais nos espaços da cidade. Mas antes o que mudou no modo de jogar agora o máximo de ocupantes para defender são seis o pokécoin tem outro sistema de controle e não há mais o sistema de prestígio nem as dinâmicas de: 1) treinar no ginásio da equipe ou 2) ter que vencer todos os defensores para obter a vitória e itens ao atacar.

Para participar de uma Raid é preciso ter um pas- se especial que é liberado diariamente nas pokéstops dos ginásios. Ela pode reunir jogadores das três equipes para que possam derrotar um pokémon com CP elevado no tempo disponível para a batalha, eles são divididos em níveis de 1 a 4 - esse último pode chegar a quase 35000 CP. O jogador pode entrar em um duelo com o "chefão" sozinho, mas dependendo do CP as chances de ganhar são melhores quando os jogadores se unem em um grupo privado de até 20 participantes. Com a vitória, os usuários ganham itens como pokébolas especiais para tentar capturar o pokémon derrotado e, entre outros, "bala rara" que se converte no doce do pokémon selecionado.

Diante deste cenário, o jogador precisa interagir com pessoas próximas para poder entrar no grupo com mais integrantes, para isso a tão temida barreira de conversar com estranhos na rua precisa ser quebrada ainda mais se houver um pokémon raro que não figura em sua pokédex. Mas é claro que essa interação social pode ser previamente acordada com amigos próximos, ou com estranhos a partir de inúmeros grupos no Facebook ou no serviço de mensagens WhatsApp, entre muitos outros meios.

Vale destacar que alguns aspectos diferenciam as realidades virtual e aumentada. O uso de dispositivos tecnológicos em ambientes fechados é uma das principais pontuadas por Kirner e Siscoutto, considerando suas especificidades técnicas:

[...] enquanto a realidade virtual depende de equipamentos de visualização, como monitor, projetor e capacete, normalmente utilizados em ambientes fechados, a realidade aumentada não apresenta esta restrição com dispositivos misturadores, podendo ser usada em qualquer ambiente (fechado ou aberto), sendo, portanto mais abrangente e universal (Kirner, Siscoutto, 2007, p. 5).

É oportuno observar como algumas características do game podem envolver o jogador numa experiência imersiva e lúdica. O usuário precisa concentrar sua atenção para "mergulhar" no universo de Pokémon Go, assim como é necessário em jogos analógicos e digitais. A diferença é que as cidades são o próprio cenário de Pokémon Go, com toda a movimentação de pedestres, veículos, estímulos visuais e sonoros da área explorada, estado de atenção que ao mesmo tempo o caracteriza como menos imersivo.

Desde que o jogo veio a público, tem sido um tal de gente andando distraída pelas ruas, com os olhos grudados no celular, à procura dos bichinhos. A ponto de a polícia de Melbourne, na Austrália, emitir um alerta pedindo às pessoas que prestem atenção em riscos reais, como carros passando e obstáculos na calçada. Já a polícia de Goochland, no estado americano da Virgínia, se viu forçada a avisar que o jogo não é desculpa para entrar na propriedade alheia sem autorização. Até o Museu Memorial do Holocausto dos EUA, em Washington, foi "invadido" por adeptos do game, ao que o diretor da instituição reagiu dizendo que "jogar 'Pokémon Go' num memorial dedicado a vítimas do nazismo é extremamente inapropriado" (Matsuura, 2016). 
Nesse aspecto, observa-se que as indicações da localização dos monstrinhos facilitam o jogador a buscar certas áreas que não estariam em seu roteiro cotidiano. Sendo assim, caberia questionar se Pokémon Go e outros jogos com tecnologias de RA estariam transformando o modo de explorar a cidade? Surgiria ali uma nova relação do indivíduo com a cidade e com os outros jogadores? Que sensorialidades estariam sendo modificadas e/ou estimuladas? Quais as habilidades de comunicação e sociabilidade os jogadores estariam desenvolvendo? Essas são questões que levantamos diante desses comportamentos trazidos com a disseminação de Pokémon Go.

Quem não joga ou mesmo conhece o jogo já deve imaginar que não é em todo o espaço da cidade que há milhares de seres virtuais espalhados. Os pokémons como qualquer outra coisa (plantas, animais, produtos e serviços) transitam por lugares específicos, por exemplo, na cidade do Rio de Janeiro as áreas entre a Zona Sul e Centro são as que têm presença garantida, onde há a maior concentração de pontos turísticos.

Para conseguir determinados monstrinhos, o usuário que mora longe dessas áreas com maior oferta vai a fóruns para saber onde estão os "ninhos" de pokémons, denominação criada pelos usuários para se referir aos que ficam em excesso por determinado período. Um exemplo desses ninhos é a Lagoa Rodrigo de Freitas, onde o jogador irá encontrar, sem dúvidas, um Magikarp (pokémon aquático). Nesses grupos os usuários também buscam parceiros para batalhar nas Raid. Não seria exagero considerar que o jogo estimula a descoberta de algumas ruas do bairro e da própria cidade ao incitar que transite por diferentes regiões para pegar determinado pokémon, bem como a memória de algu- mas imagens de grafites que ornam a pokéstop e já não estão mais lá.

Algumas listas na internet mostram quais pokémons são mais encontrados em regiões específicas do Rio de Janeiro. Por exemplo, no site TechTudo ${ }^{18}$ há indicações de dragões em áreas turísticas como o Pão de Açúcar. Os lutadores concentram-se em lugares de culto ao corpo, como academias de ginástica e o estádio do Maracanã. Os venenosos ficam em áreas poluídas, como a área alagada da Favela da Maré e Ilha do Governador Já os fantasmas gostam de estacionamentos, como do Edifício Garagem, no Centro, e ainda os Shoppings Tijuca e Rio Sul. No Parque Lage, estão os voadores, acostumados a áreas verdes e parques. Os elétricos "gostam" do campus de universidades. Essas indicações de certa forma estimulam os jogadores a explorar territórios que não estão no seu perímetro de circulação.

Constatamos, durante as nossas observações e buscas de relatos de experiência jogador-cidade-tecnologia, que diferentes fóruns e grupos de Facebook sobre o jogo têm informações ligadas diretamente às mecânicas, regras e tipos de pokémons. Por isso, consideramos necessário para a investigação que uma de nós (sendo assim pesquisadora-jogadora) trouxesse uma descrição dessa experiência em primeira pessoa, e por que não, com o novo sistema de batalha Raid? O jardim do Museu da República/Palácio do Catete, localizado no bairro do Catete, Rio de Janeiro, foi cenário de duas batalhas contra os chefões de Pokémon Go e da observação de como pequenos grupos se formam rapidamente quando o ovo se quebra e libera o boss.

"A primeira experiência numa Raid de nível 4, aconteceu no dia 24 de junho. O Pokémon raro que surgiu foi o enorme Snorlax de quase 26 mil de CP, que já constava na minha pokédex, mas essa era a minha primeira Raid. Antes de adentrar no ginásio e gastar o meu passe, sentei-me num dos bancos relativamente próximo do ginásio e abri um livro que já estava lendo para, de tempos em tempos, observar o movimento, mas sempre com o jogo ativo na tela do aparelho. Na verdade, diante do lançamento, muitas eram as informações contraditórias sobre como seria o sistema de jogo, uma delas dizia que era preciso ter no mínimo o nível 30, e eu estava ainda no nível 29.

"Percebendo a movimentação e conversa perto do ginásio, resolvi me aproximar e perguntar sobre a Raid, ao que me disseram que não tinha a restrição que eu pensei existir. Mas antes, tive que ligar o meu celular ao seu aparelho de sobrevivência, o famoso carregador-portátil que qualquer jogador precisa ter sempre em mãos. A interação com o jogo nesse módulo é bastante interessante, porque antes de começar uma batalha desse tipo é preciso entrar num dos grupos já formados; dependendo do relógio de seu aparelho você pode não entrar a tempo na batalha com o grupo; sem contar que houve jogadores em que o jogo fechou no meio; quanto maior for o grupo, mais rápida é a luta, ainda mais que há tempo para conseguir subjugar o boss. Só conseguimos quando entramos com pelo menos cinco jogadores, se a memória não me falha, foram três tentativas antes. E sim, eu consegui capturar o Snorlax!

"No dia dois de julho apareceu o Lapras com aproximadamente 22 mil de $\mathrm{CP}$, ser raro tão aguardado por mim. Estava em casa quando resolvi conferir o jogo, eis que surge o temporizador do ginásio informando que aquele ovo tinha acabado de eclodir. Era um dia frio, para os padrões de qualquer carioca, e para completar 
a enxaqueca era dona de minha mente. Mas eu não podia deixar de passar essa oportunidade. Andei o mais rápido que pude e no caminho notei que tinha um outro rapaz andando tão apressado quanto. Claro que apertei o passo e me distanciei um pouco, o meu celular não estava visível, mas não é bom dar "bobeira". Ao chegar na segurança do jardim, constatei o que tinha imaginado no trajeto. Ele também era um treinador de Pokémon.

"Depois de uns cinco minutos surgiram mais pessoas que começaram a conversar entre si, por causa de minha "situação" eu estava mais quieta ainda. Entrei sozinha na Raid esperando cair num grupo privado, mas não aconteceu necessariamente isso, tinha apenas mais um jogador nele e é óbvio que fomos derrotados. Superando a minha dor, e começando a sentir calor por causa da quase corrida até o jardim e da emoção de estar tão próximo de pegar um novo Pokémon para a coleção, resolvi perguntar qual era o grupo formado. Nesse meio tempo um grupo derrotou o Lapras, mas no fim não conseguiram capturá-lo. Consegui entrar em um com mais sete integrantes rapidamente acabamos a batalha. Não vou negar que fiquei preocupada de não conseguir pegá-lo, mas consegui quase no fim das bolas especiais! Sim, devo dizer que o sentimento de conquista define bem a situação! Nesse mesmo dia eu descobri que um jogador nível 16 também pode entrar numa batalha e que o número de pokémons que podem desafiar o boss pode passar de seis, pois esse jogador que tinha mais uma conta, a outra com nível 34, continuou jogando com os jogadores que apareciam para enfrentar o Lapras. Outros jogadores também já estavam planejando ir para o bairro do Leme atrás de outro boss-pokémon". Nesse aspecto, nota-se o quanto os partici- pantes precisam se comunicar e estar em grupo para conquistar certos objetivos. Essa dinâmica poderá ser observada em larga escala a partir do dia 22 de julho, quando a Niantic convoca através de seu site ${ }^{19}$ todos os jogadores de Pokémon Go para o primeiro desafio global, incluindo o Brasil. Em Chicago, haverá o Pokémon Go Fest onde serão fornecidas dicas de como liberar recompensas especiais replicando as orientações em todo o mundo. Em determinados horários, as criaturas do tipo fogo, água, grama, elétrico, pedra e normal serão contabilizadas em um ranking e, caso a meta de capturas seja alcançada, os jogadores terão bônus nos doces, experiência, Stardust, diminuição na distância dos ovos, redução na quilometragem do parceiro e taxa maior de encontro, respectivamente. Para quem não está em Chicago, a proposta é capturar neste dia o máximo de criaturas possíveis para obter uma medaIha. Se no prazo previsto conquistarem a de bronze, os bônus mencionados acima vão valer por $24 \mathrm{~h}$, enquanto a de prata duplica esse tempo. Caso os jogadores cheguem à ouro, o Mystery Challenge será habilitado em Chicago, com recompensa global nos dias 23 e 24 de julho. Com esse evento, espera-se alcançar em escala simultânea e global níveis de interação e sociabilidade nunca antes testados através do aplicativo.

\section{Algumas considerações}

Esse exercício não encerra o debate, ao contrário abre outras vias de reflexão e questionamentos. A caça de pokémons pelo espaço urbano e a dedicação dos jogadores para alcançar determinados objetivos, como a pesquisadora Alessandra Maia nos relatou, abre lacunas para diversas questões sobre sociabilidade, interação, diferentes níveis de sensorialidades no contexto cida- de-jogo-tecnologias. Durante essa atividade, notamos uma outra esfera sensível em Pokémon Go: a questão da privacidade. Além de registros de invasão de áreas particulares, o acesso às fotos e às imagens dos ambientes geradas dentro do aplicativo também é discutido. O registro por um jogador envolvendo pedestres em uma calçada poderia ser divulgado? Quais os limites territoriais para jogadores? Essas são algumas questões que devem ser respondidas ao longo do tempo.

Com esse artigo, procuramos levantar algumas formas de interação e sociabilidade de jogadores de Pokémon Go no Rio de Janeiro. Além das modificações e diferentes apropriações por meio da caça e treino de pokémons, observamos a relação do jogador com a cidade, a partir da perspectiva de uma cognição (Varela, 1994; Varela, Thompson, Rosch, 2000) em que cérebro, corpo, objetos e ambiente estão associados de forma inextricável e são igualmente importantes para analisar um processo. Como método, utilizou-se a observação participante, além da coleta de dados em fóruns e sites especializados no game, e ainda bibliografia específica. Por tudo o que foi observado durante a produção deste trabalho, nota-se que as formas de sociabilidade e apropriações em Pokémon Go são inúmeras e estão se alterando, dentre outras razões, a cada evolução e novidade do jogo. Esse artigo não encerra qualquer discussão, mas sim é ponto de partida para outras investigações e questões relativas ao game.

\section{Referências}

AZEVEDO, Sandro. Sentidos estéticos e experiências sensíveis na Ciberpublicidade: ações de realidade aumentada. In: ATEM, Guilherme; OLIVEIRA, Thaiane; AZEVEDO, Sandro (orgs.). Ciberpublicidade: discurso, 
experiência e consumo na cultura transmidiática. Rio de Janeiro: E-papers, 2014.

CHANDLER, Heather Maxwell. Manual de Produção de Jogos Digitais. Porto Alegre/RS: Bookman, 2012.

COELHO, Cássio. Pokémon GO: Niantic volta a banir contas de trapaceiros no jogo. Optclean Tecnologia. 24 de jan. 2017. Disponível em: <https://optclean.com. br/pokemon-go-niantic-volta-a-banir-bots/>. Acesso em: 13 fev. 2018.

ERMI, Laura; MÄYRÄ, Frans. Fundamental components of the gameplay experience: analysing immersion. In: GÜNZEL, Stephan; LIEBE, Michael; MERSCH, Dieter (Orgs.). DIGAREC Keynote-Lectures 2009/10. Potsdam: University Press, 2011. Disponível em: <https:// goo.gl/md6XPR>. Acesso em: 07 fev. 2018.

FOLHA DE SÃO PAULO. Número de smartphones em uso no Brasil chega a 168 milhões, diz estudo. São Paulo. 15 abr. 2016. Disponível em: <http://www1.folha. uol.com.br/mercado/2016/04/1761310-numero-desmartphones-em-uso-no-brasil-chega-a-168-milhoesdiz-estudo.shtml>. Acesso em: 14 jul. 2017.

GALEANO, Eduardo. Depoimento na praça Catalunha durante o evento La Acampada, Barcelona, 24 maio 2011. [vídeo]. Disponível em: <https://www.youtube. com/watch?v=mdY64TdriJk>. Acesso em: 07 jul. 2017.

HUIZINGA, Johan. Homo Ludens: o jogo como elemento da cultura. São Paulo: Perspectiva, 2007.
IMDb. Pokémon. Disponível em: <http://www.imdb. com/title/tt0176385/>. Acesso em: 14 jul. 2017.

JUUL, Jesper. Half-Real: Video Games between Real Rules and Fictional Worlds. Cambridge, MA: MIT Press, 2005.

KAWA, Luke;KATZ,Lily.TheseCharts ShowThatPokemon Go Is Already in Decline. Bloomberg. 22 ago. 2016. Disponível em:< https://www.bloomberg.com/news/ articles/2016-08-22/these-charts-show-that-pokemongo-is-already-in-decline>. Acesso em: 14 jul. 2017. KIRNER, Claudio; SISCOUTTO, Robson. Realidade Virtual e Aumentada: Conceitos, Projeto e Aplicações. Petrópolis: Simpósio, 2007. Disponível em: <http://www. ckirner.com/download/livros/Livro-RVA2007-1-28.pdf>. Acesso em: 07 fev. 2018.

MARTINO, Luís Mauro Sá. Teoria das Mídias Digitais: linguagens, ambientes, redes. Petrópolis/RJ: Vozes, 2014.

MATSUURA, Sérgio. Pokémon Go altera rotina de cidades e preocupa autoridades. $\mathbf{O}$ Globo. Rio de Janeiro, 13 jul. 2016. Disponível em: <https://goo.gl/fVfqMy>. Acesso em: 14 jul. 2017.

MÄYRÄ, Frans. An Introduction to Game Studies: games in culture. London: Sage, 2008.

MONTEIRO, Rafael. Onde encontrar cada tipo de Pokémon em Pokémon Go. TechTudo. 19 set. 2016. Disponível em: <http://www.techtudo.com.br/dicas-e- tutoriais/noticia/2016/08/onde-encontrar-cada-tipode-pokemon-em-pokemon-go.html>. Acesso em: 14 jul. 2017.

MURRAY, Janet H. Hamlet no Holodeck: o futuro da narrativa no ciberespaço. São Paulo: Itaú Cultural/ Unesp, 2003.

NERDBLOID. Pokémons evoluindo no Rio de Janeiro. 07 jul. 2016. Disponível em: <https://nerdbloid.net/ nerdhumor/pokemons-evoluindo-no-rio-de-janeiro/> Acesso em: 07 fev. 2018.

NEWZOO. Analysis of Pokémon Go: a success two decades in the making. 30 set. 2016. Disponível em: $<$ https://newzoo.com/insights/articles/analysispokemon-go/>. Acesso em: 14 jul. 2017.

NIANTICLABS. Pokémon Go. What's changing in Pokémon Go? Disponível em: <https:// support.pokemongo.nianticlabs.com/hc/en-us/ articles/115009004687-What-s-changing-inPok\%C3\%A9mon-GO->. Acesso em: 14 jul. 2017.

Raid Battles: Come together with Trainers of all teams to deseat the Raid Boss. Disponível em: $<$ https://support.pokemongo.nianticlabs.com/hc/enus/articles/115009004747-Raid-Battles>. Acesso em: 14 jul. 2017.

Updates. Disponível em: <http://pokemongo. nianticlabs.com>. Acesso em: 14 jul. 2017.

OGRO. Fui jogar pokémon go no Rio de Janeiro e olha 
no que deu. Disponível em: <http://www.naoentreaki. com.br/11327128-fui-jogar-pokemon-go-no-rio-dejaneiro-e-olha.htm>. Acesso em: 14 jul. 2017.

OLIVEIRA,Thaiane;ANDRADE,Luiz.Umjogoderealidades e ficcionalidades. Ciberlegenda, 2014. Disponível em: <http://www.proppi.uff.br/ciberlegenda/um-jogo-derealidades-e-ficcionalidades $>$. Acesso em: 15 ago. 2016.

PRASS, Ronaldo. Pokémon GO: saiba os riscos e vantagens de usar GPS 'fake' para simular a localização. G1. 06 de ago. 2016. Disponível em: <http://g1.globo. com/tecnologia/blog/tira-duvidas-de-tecnologia/post/ pokemon-go-saiba-os-riscos-e-vantagens-de-usargps-fake-para-simular-localizacao.html>. Acesso em: 13 fev. 2018.

PRIMO, Alex (org.). Interações em rede. Coleção Cibercultura. Porto Alegre: Sulina, 2013.

ROGERS, Scott. Level UP: um guia para o design de grandes jogos. São Paulo: Blucher, 2012.

SALEN, Katie; ZIMMERMAN, Eric. Regras do Jogo: fundamentos do design de jogos: principais conceitos. Vol. 1 - 4. São Paulo: Blucher, 2012.

SCHELL, Jesse. The art of Game Design. Burlington, MA: Morgan Kaufmann, 2008.

SCHUYTEMA, Paul. Design de games: uma abordagem prática. São Paulo: Cengage Learning, 2016.

SORVETERU. Pokemon versão Rio de Janeiro. 2016. 1 Trabalho apresentado no GP Games do XVII Encon- (0:59s). Disponível em: <https://www.youtube.com/ watch?v=f4BHypOBJys $>$. Acesso em: 07 fev. 2018.

SWATMAN, Rachel. Pokémon Go catches five new world records. Guinness World Records. 10 ago. 2016. Disponível em: <http://www.guinnessworldrecords. com/news/2016/8/pokemon-go-catches-five-worldrecords-439327>. Acesso em: 14 jul. 2017.

VAIANO, Bruno. 7 lugares inusitados para capturar um Pokémon, 2016. Disponível em: <https://goo.gl/ uvd7mo>. Acesso em: 14 jul. 2017.

VARELA, Francisco. Conhecer, as ciências cognitivas e perspectivas. Lisboa: Instituto Piaget, 1994

; THOMPSON, Evan; ROSCH, Eleanor. A mente

corpórea. Lisboa: Instituto Piaget, 2000.

VELOCCI,Carli.Nianticdizquevaibanirpermanentemente quem trapaceia em Pokémon Go. Gizmodo Brasil. 15 de ago. 2018. Disponível em: <http://gizmodo.uol.com. br/niantic-banir-pokemon-go/>. Acesso em: $13 \mathrm{de} \mathrm{fev}$ 2018.

VIEIRA, Douglas. Niantic permite que alguns jogadores banidos retornem a Pokémon GO. TecMundo. 30 ago. 2016. Disponível em: <https://www.tecmundo. com.br/pokemon-go/108970-voltou-niantic-permitejogadores-banidos-retornem-pokemon-go.htm>. Acesso em: 14 jul. 2017.

Notas tro dos Grupos de Pesquisa em Comunicação, evento componente do $40^{\circ}$ Congresso Brasileiro de Ciências da Comunicação. Participou deste texto Kerolayne Marinho.

2 Doutora em Comunicação pela Universidade Federal do Rio de Janeiro (2002). Mestre em Comunicação pela Universidade Federal do Rio de Janeiro (1996). Professora Associada da Faculdade de Comunicação Social da Universidade do Estado do Rio de Janeiro (FCS/UERJ - Rua São Francisco Xavier, 524 - 10 andar - Bloco A - sala 10129. Maracanã. Cep: 20550013 - Rio de Janeiro, RJ).E-mail:fatimaregisoliveira@gmail.com.

3 Doutoranda em Comunicação pela Universidade Estadual do Rio de Janeiro (2014). Mestre em Comunicação pela Universidade Estadual do Rio de Janeiro (2014) (Programa de Pós-Graduação em Comunicação - Universidade Estadual do Rio de Janeiro - Rua São Francisco Xavier, 524, $10^{\circ}$ andar, sala 10.129, bloco F, Pavilhão João Lyra Filho Maracanã. Cep: 20550-900. Rio de Janeiro - RJ). E-mail: ale.led@gmail.com.

4 Doutoranda em Novas Tecnologias da Comunicação pela Universidade Estadual do Rio de Janeiro (2017). Mestre em Comunicação pela Universidade Estadual do Rio de Janeiro (2010). (Programa de Pós-Graduação em Comunicação - Universidade Estadual do Rio de Janeiro - Rua São Francisco Xavier, 524, $10^{\circ}$ andar, sala 10.129, bloco F, Pavilhão João Lyra Filho Maracanã. Cep: 20550-900. Rio de Janeiro - RJ). E-mail: renata. monty@gmail.com.

5 Desenvolvido pela Niantic Inc., pode ser baixado gratuitamente, mas há vendas de espaço e de itens em seu interior, por isso é considerado um jogo freemium. 
6 Para entender como a modalidade funcionam confira as notícias de sites de notícias como G1 e Tecmundo; Gizmodo especializado em notícias relacionadas com o universo gamer, bem como o site mantido por fãs do jogo: disponíveis em <http://g1.globo.com/tecnologia/blog/tira-duvidas-de-tecnologia/post/pokemon-go-saiba-os-riscos-e-vantagens-de-usar-gps-fake-para-simular-localizacao.html>; <https://www. tecmundo.com.br/pokemon-go/108970-voltou-niantic-permite-jogadores-banidos-retornem-pokemon-go.htm>; <http://gizmodo.uol.com.br/niantic-banir-pokemon-go/>, respectivamente. Acessos em 14 de jul 2017.Essas notícias foram publicadas em 2016, mas no início de 2017 o site Optclean voltou a falar das ações da Niantic a partir de discussões no fórum Reddit, disponível em: <https://optclean.com.br/pokemon-go-niantic-volta-a-banir-bots/>. Acesso em 14 jul. 2017.

7 Disponível em: <goo.gl/AjDDnU>. Acesso em: 14 jul. 2017.

8 Disponível em: <https://nerdbloid.net/nerdhumor/ pokemons-evoluindo-no-rio-de-janeiro/>. Acesso em: 07 de fev. de 2018.

9 Disponível em: <https://www.youtube.com/watch?$\mathrm{v}=$ f4BHypOBJys $>$. Acesso em: 07 de fev. de 2018.

10 Disponível em: <https://goo.gl/fzu9sF>. Acesso em: 14 jul. 2017.

11 Disponível em: <https://goo.gl/ry93mV>. Acesso em: 14 jul. 2017.
12 Disponível em: <https://goo.gl/2tdv9e>. Acesso em: 14 jul. 2017.

13 Pesquisa divulgada pela Folha de São Paulo. Disponível em: < https://goo.gl/wPvz1c>. Acesso em: 14 jul. 2017.

14 Criação do japonês Satoshi Tajiri, que gostava de capturar insetos, o primeiro produto foram os videogames Red e Blue para o portátil da Nintendo, o Gameboy.

15 Os pequenos monstros foram eternizados pela série japonesa em anime de mesmo nome, lançada em 1997 e no ar até hoje. Disponível em: < https://goo.gl/ hQQ7ba>. Acesso em: 14 jul. 2017.

16 Disponível em: <https://goo.gl/PuR9ji>. Acesso em: 14 jul. 2017.

17 Para conferir essas informações, mecânicas e outros dados oficiais da Niantic, acessar <https://support. pokemongo.nianticlabs.com/hc/en-us/articles/ 115009004747-Raid-Battles>. Acesso em 14 jul. 2017.

18 Disponível em: <goo.gl/f4ydTC >. Acesso em: 14 jul. 2017.

19 Disponível em: <http://pokemongo.nianticlabs.com>. Acesso em: 14 jul. 2017.

52 PORTO ALEGRE | v. 22 | n. $38|2017|$ p. $43-52$ Sessões do Imaginário 